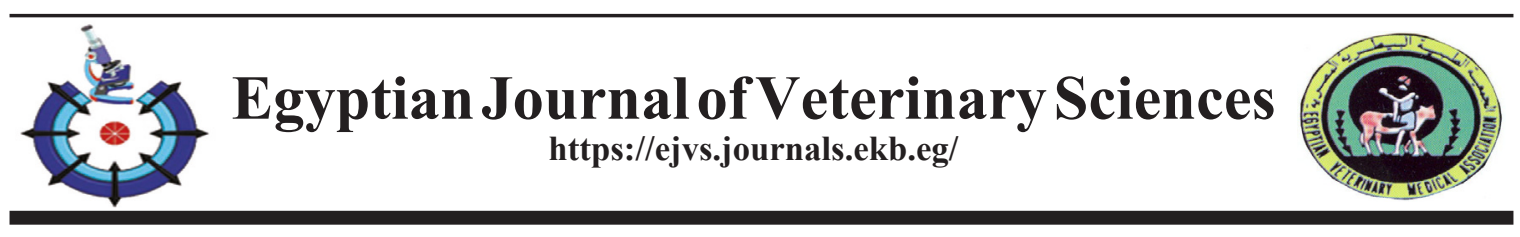

\title{
Pathomorphological Study of Liver Lesions in Sheep at Duhok Abattoir
}

Mahdi Ali Abdullah

Department of Pathology \& Microbiology, College of Veterinary Medicine, University

of Duhok, Iraq.

\begin{abstract}
$\mathbf{T}$
HE study was conducted to identification of liver lesions of sheep at Duhok abattoir from the month of May to October 2021. In the present study, 223 liver samples of sheep were examined and collected from Duhok Abattoir for pathomorphological studies. About 158 liver samples were severely infected with parasitic liver diseases, 140 it was cystic hydatidosis, 5 liver worm, and 13 samples was recorded as Hepatic cysticercoa, while the rest samples was abscesses, fatty degeneration, Congestion\& hemorrhage. The prominent gross lesions in cystic hydatidosis included hard parenchyma with congestion and presence of fibrous tissue. While fascioliasis liver enlarged, icterus, fibrosis of bile ducts. As for hepatic abscesses, it was observed visually by presence of white to yellow solid texture compositions as spherical shapes to ovals and in different sizes and distributed through and the surface of the hepatic lobes and extended, As for congestion and hepatic hemorrhage, livers have been observed as congestion with enlarged of liver and coloration of the liver tissue while fatty change the lobes of livers were enlarged, pale yellow, soft and friable with rounded edges, Histopathological examination of liver cystic hydatidosis, revealed protoscoleces attached to the germinal layer of the cyst associated with extensive fibrosis of the liver parenchyma in cases of liver with presence of different larval stage of worms inside of the bile duct in cases of liver fluke,different larval stages were seen in the bile ducts accompanied by marked cellular reaction characterized by proliferation of fibroblasts, diffuse infiltration of mononuclear inflammatory cells, hemorrhage, abscesses with degeneration of hepatocyte. Biliary hyperplasia and fibrosis were also observed in the infected liver.
\end{abstract}

Keywords: Liver, Lesions, Histopathology.

\section{Introduction}

The liver is responsible for metabolisms of carbohydrates, Proteins, fats, and other important elements to sustaining the organism as well as to expel toxic substances from the body through the bile secretion $[1,2]$. The main blood circulation of the liver is represented with the hepatic artery that brings an oxygenated blood circulatory system and while the portal artery it brings the blood loaded with absorbed nutrients from intestine to the liver [3]. Liver tissue is mainly composed of cells called hepatocytes which are arranged in rows of perpendicular to the central vein, Histologically the liver tissue is composed of the central vein, which is surrounded by hepatocytes and arranged as cord and consisting of a pair of hepatocytes that's aligns backwards and creating a small space Known as Diss of space which serves to collect bile matter secreted from hepatocytes and transported it to the portal area which is mainly consist from fibroblasts, lymphatic vessels, blood vessels and bile ducts, while the space between hepatocytes cells is known as liver sinusoids[3].

Due to the important role of liver in the metabolizing and excreting nutrients, furthermore the large blood supply coming from the main

Corresponding authors: Mahdi Ali Abdullah, Email: Mahdi.ali@uod.ac, Tel. 07507344094

(Received 07/10/2021; accepted 20/12/2021)

DOI. 10.21608/ejvs.2021.99984.1304

(C)2022 National Information and Documentation Centre (NIDOC) 
circulation and portal circulation of the intestine, so the liver suffers from many pathological lesions due to different etiologies agents[4]. The major sources of etiologies affections are from pathogenic organisms like parasitic infections, bacterial infections, nutrition, and toxins $[5,6]$

Also, the percentage and prevalence of Liver disease is greatly influenced by many factors, including season, temperature, breeding and genetic predisposition and among the most important diseases that are recorded in Iraq with high ration as previous studies is liver worms $[7,8]$, Also, the infections due to the to the larvae of Echinococcus granulosus worms, known as hydatid cysts, liver worm and cysticercososis which is widely spread and at high rates and varies from one study to another according to the different regions and governorates of Iraq [9,11]. As well as many studies was conducted and recorded in Iraq about the liver lesions like as inflammatory conditions like congestion, hemorrhage, degeneration and Liver abscesses, which were primary or secondary, infected the liver $[12,13]$. Therefore, for the above reasons, it was planned to conduct this study to identify the gross and tissue lesions and the percentage of lesions of the livers in sheep slaughtered at Duhok Abattoir.

\section{Materials and Methods}

Livers of 223 sheep carcasses were examined during the period extended from May to October 2021. A detailed gross examination of the lesions with respect to size, color and consistency were recorded and photographed. After slaughtering, samples were collected from lesions of infected livers in clean plastic packs and then transferred it to cool box to Duhok research center department of histopathology for further investigation of gross and microscopical changes. Histopathological observation was carried out by trimming the samples from the livers with a sharp knife into small pieces about $1 \mathrm{~cm}$ size and fixed in $10 \%$ neutral buffered formalin were processed by routine paraffin-embedding technique, dehydrated, cleared and impregnated in melted paraffin. After impregnation of the samples, they were blocked with paraffin wax. Later, the prepared blocks were sectioned by rotary microtome into 4-5 $\mu \mathrm{m}$ thick sections were stained by routine Haematoxylin and Eosin (H\&E) [14].

The stained sections were examined under light microscope and photographed by using digital computerized camera cannon (Leica, Germany). The results of gross and histopathology were analyzed and interpreted.

\section{Results}

\section{General prevalence rate}

The incidence of liver lesions in slaughtered sheep at Duhok abattoir during the period of study from May to October 2021 illustrated in Table 1.

The results of the current study showed that the total incidence of lesions of Liver in sheep was $99.8 \%$. The highest infections of liver lesions was in our study recorded as hydatid cyst $62.8 \%$, and lowers percentage lesions was with Liver worms $2.2 \%$, while inflammations was $4.4 \%$, and other ratio of lesions as fatty changes $15.6 \%$, and liver abscesses was 8.9 .

\section{Histopathological examination of liver lesions}

Result show the liver with liver worm appears an irregular outline, and the color was pale with firm consistency, the most commonly affected part appears at right lobe while some other lesions characterized by hepatic fibrosis, ischaemic area appears as yellow in color as jaundice with thrombosis of large blood vessels and damage flukes in the small bile ducts (Fig. 1).

TABLE 1. Percentage ratio of liver lesions .

\begin{tabular}{lll}
\hline Type of lesions & Number of samples & \% of affected samples \\
\hline Fatty changes & 35 & 15.6 \\
Hydatid cyst & 140 & 62.8 \\
Liver worms & 5 & 2.2 \\
Liver abscess & 20 & 8.9 \\
Congestion\& hemorrhage (inflammation) & 10 & 4.4 \\
Cysticercus Cyst & 13 & 5.8 \\
\hline Total & 223 & 99.8 \\
\hline
\end{tabular}




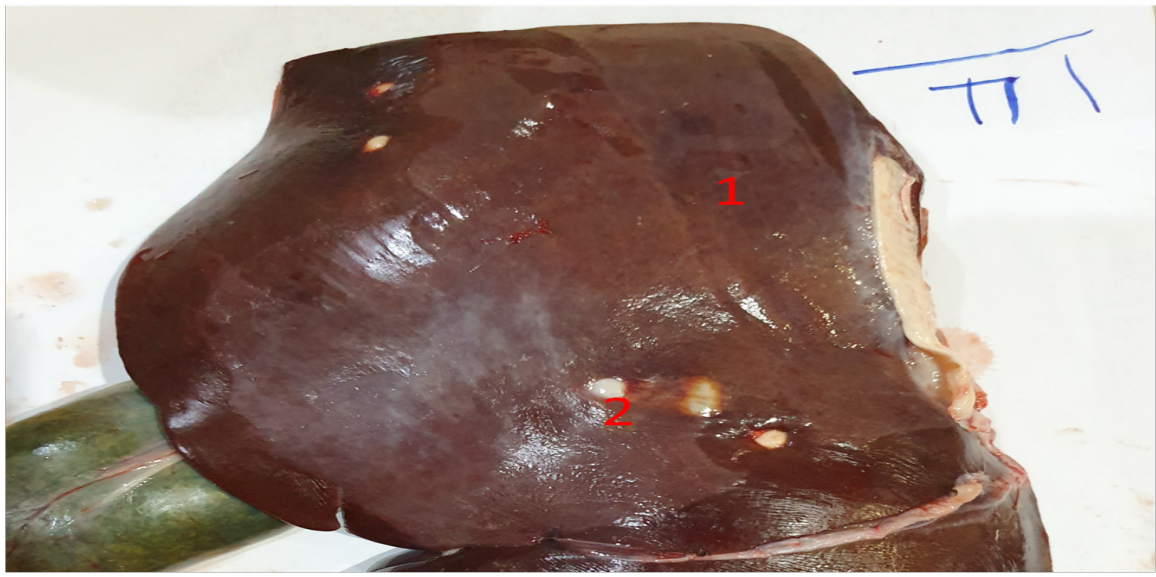

Fig. 1. Macroscopical picture of liver affected with liver fluke showing congestion (1) and enlargement of liver with the presence of calcified areas (2).

Histologically showed presence of different larval stage of worms inside of the bile duct and lumen filled with eggs of parasite beside the hyperplasia of epithelial cells lining and infiltration of inflammatory cells around bile duct and fibrosis (Fig. 2).

While the macroscopical lesions of hydatid cyst after postmortem examination of liver revealed the presence of many of cyst in variable size in the surface of liver, bright white in color with presence of many of protoscolices and clear hydatid fluid, indicating viability (Fig. 3).

Histologically the cysts consist of three layers and had a laminated membrane revealing presence of numerous protoscolices from within or outside the brood capsule. The cyst wall was surrounded by the adventitial layer which in turn was surrounded by the inflammatory cells comprising of eosinophils, mononuclear cells and a few of fibroblasts. The adjacent area of liver parenchyma showed with hemorrhage diffuse infiltration of mononuclear inflammatory cells. (Fig. 4 A and B).

While hepatic abscesses, it was observed visually by presence of white to yellow solid texture compositions as spherical shapes to ovals and in different sizes and distributed through the surface of the hepatic lobes and extended. When lesions cut it was observed to consist of a yellowcolored cheese center surrounded by a casing of White fibrous tissue extended inside liver tissue (Fig. 5).

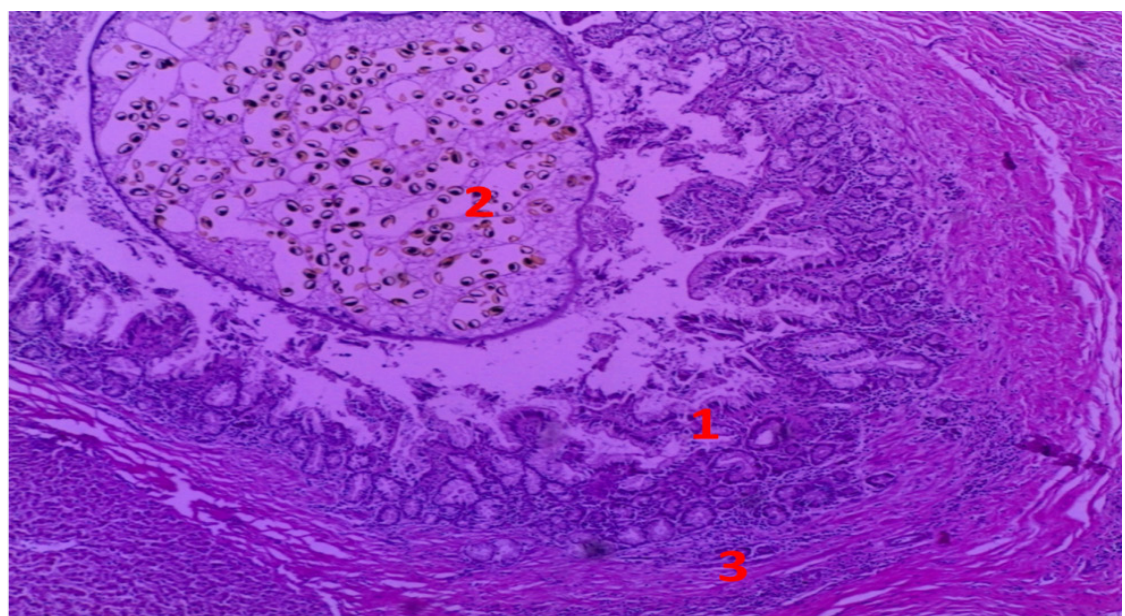

Fig. 2. Microscopical changes of liver with Fasciola hepatica shows biliary epithelia changes (1), presence of liver fluke inside bile duct (2), the bile ducts are surrounded by inflammatory response and fibrosis (3). [H\&E, 10x]. 


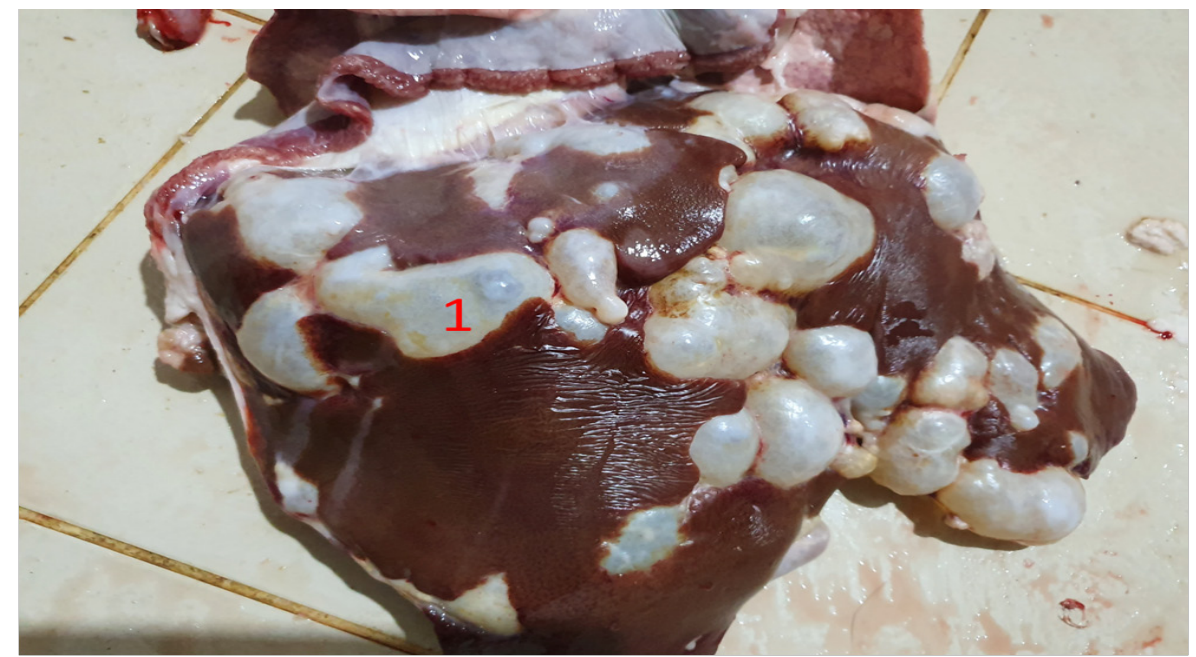

Fig. 3. Macroscopical picture of liver showing presence of different cysts of Echinococcus granulosus which are varies in size in the surface of live and attached superficially with live parenchyma with clear hydatid fluid (1).

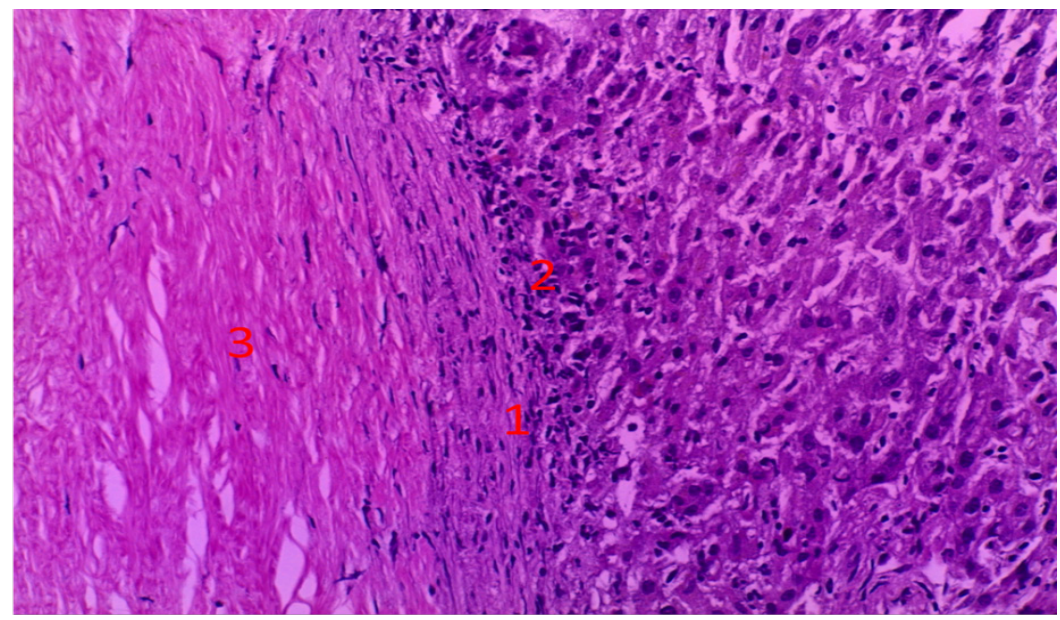

Fig. 4A. Microscopical changes of liver affected with hydatidosis revealing laminated cyst wall (1),surrounded by mononuclear inflammatory cells (2), followed by a layer of fibroblastic cells (3). [H\&E, 10x].

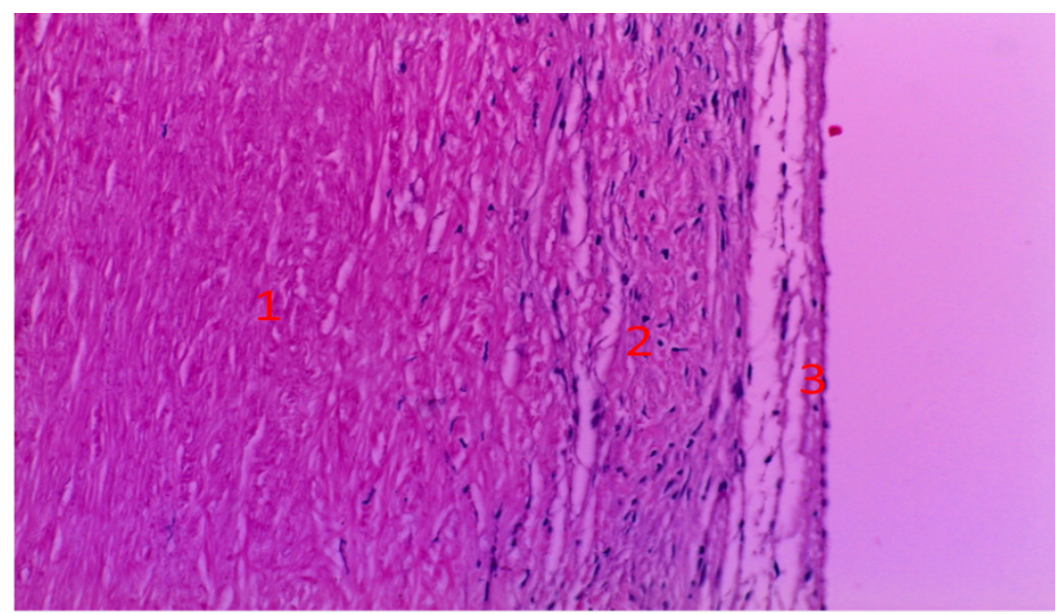

Fig. 4B. Microscopical structures of hydatid cyst, adventitia (1), laminated membrane(2) and germinal epithelium (3).[H\&E., 10x].

Egypt. J. Vet. Sci. Vol. 53, No. 2 (2022) 


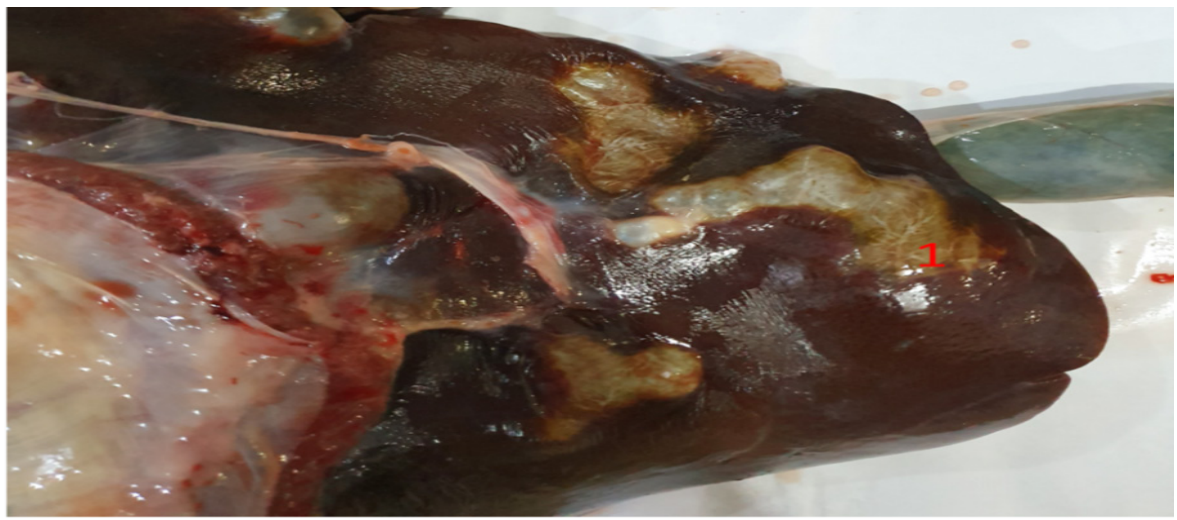

Fig. 5. Macroscopical picture of liver showing presence of abscesses white to yellow in color and solid in texture (1), spherical to ovals in shape and in different sizes and distributed through the surface of hepatic lobes and extended .

Histologically there was sever infiltration of mononuclear inflammatory cells within the hepatic lobules and portal area, it has also been noted that these lesions is consist of necrotic area with infiltration of polymorphnuclear inflammatory cells and mononuclear inflammatory cells mainly lymphocytes cells which is separated from normal hepatic cells (Fig. 6)

As for congestion and hepatic hemorrhage, livers have been observed severe congestion with enlarged of liver, (Fig. 7), furthermore it was noticing the coloration of the entire liver tissue in blood color when making cuts in it. Histologically presence of red blood cells between hepatic cells and in large quantities as well as infiltration of inflammatory cells, also there is vacuolation of hepatic cells and a mild infiltration of inflammatory cells around the central vein and liver tissue (Fig. 8)
Result of fatty changes in macroscopic examination, the lobes of livers with notable fatty change were observed enlarged, pale yellow, soft and friable with rounded edges (Fig. 9).

The present result of histopathological lesions was characterized by hepatocyte swelling and vacuolation, darkening and compression of their nuclei (pyknosis), and in some cases, pushing nuclei to the border of the cell (Fig. 10).

In cases of hepatitis cystecercosa result show in grossly liver were firm, enlarged and small cysts were attached superficially with the liver parenchyma (Fig. 11).

Microscopical examination of hepatitis cystecercosa shows inflammatory reaction around the cyst with eosinophils and fatty changes, dilatation of sinusoids, fibrosis and proliferation of bile duct (Fig. 12).

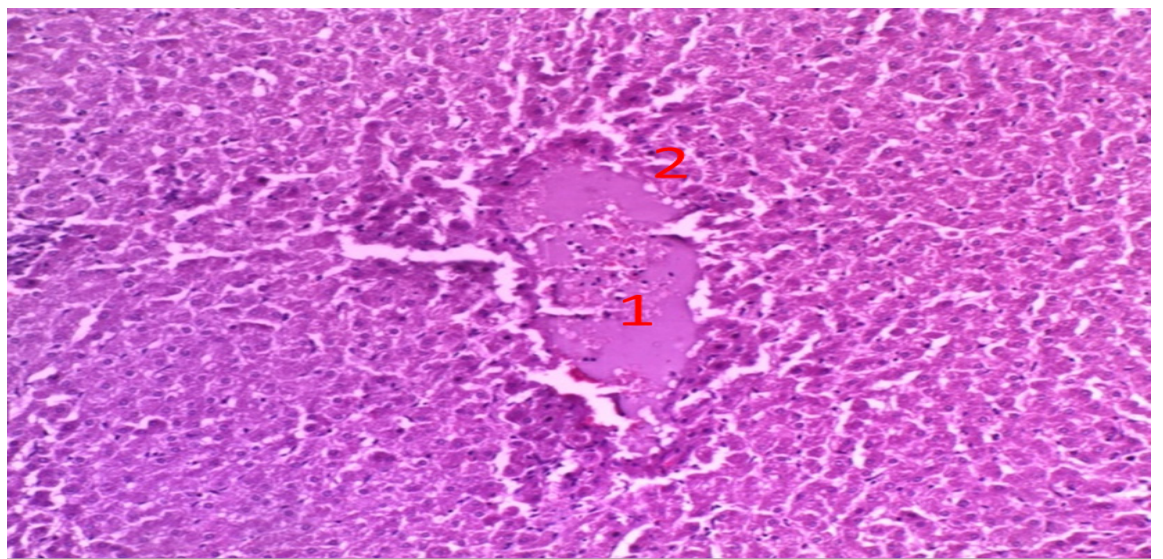

Fig. 6. Microscopical changes of liver with liver abscesses shows an early abscess formation (1), consisting of circular necrotic tissue surrounded by zone of inflammatory cells(2). [H\&E, 10X]. 


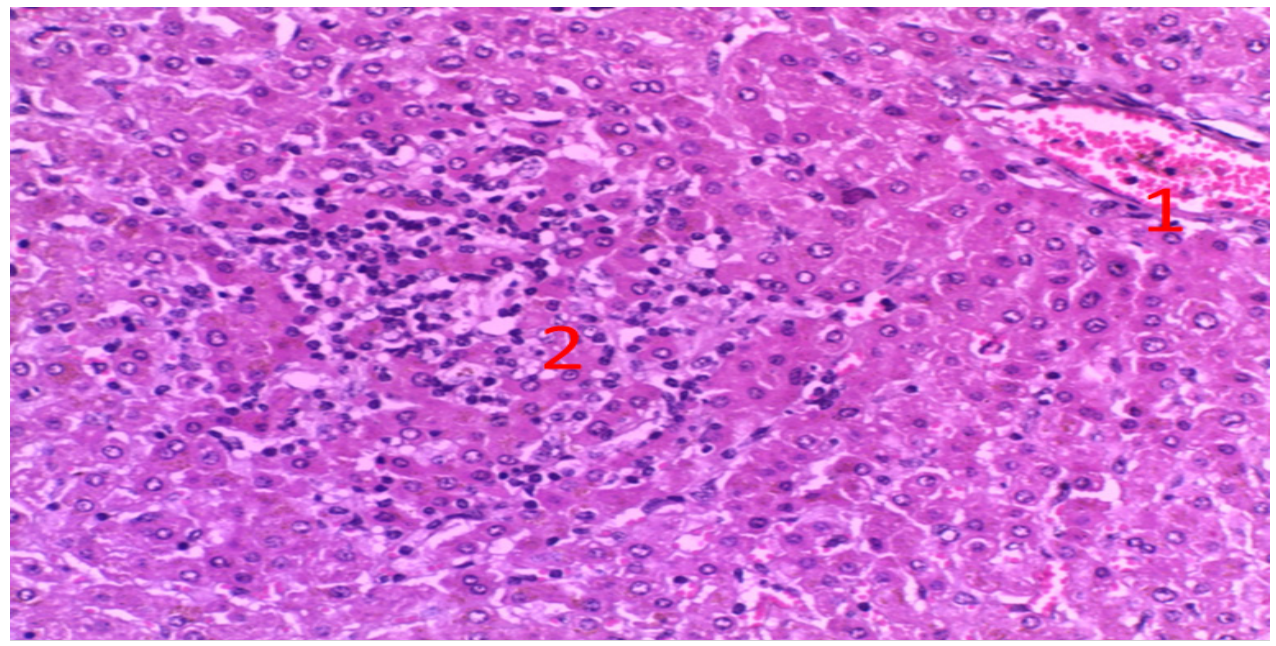

Fig. 7. Microscopical changes of liver shows sever congestion of portal vein(1), with infiltration of mononuclear inflammatory cells (2).[H\&E].

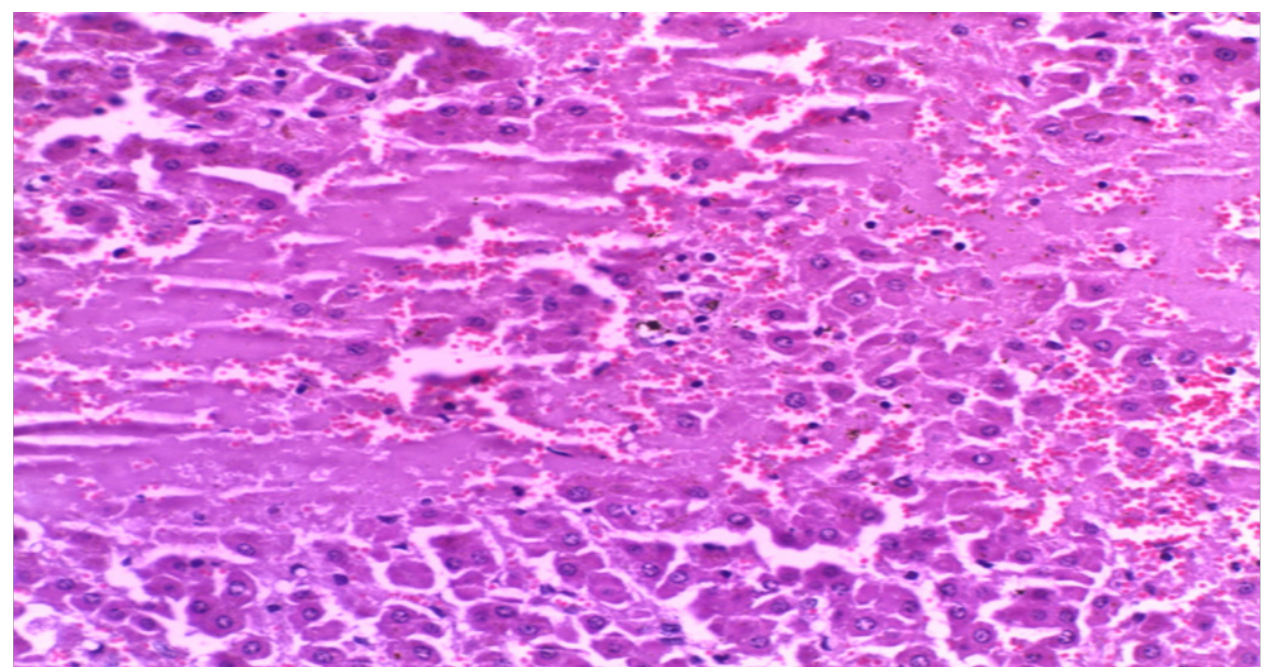

Fig. 8. Microscopical changes of liver shows sever congestion of hepatic cells.[H\&E].

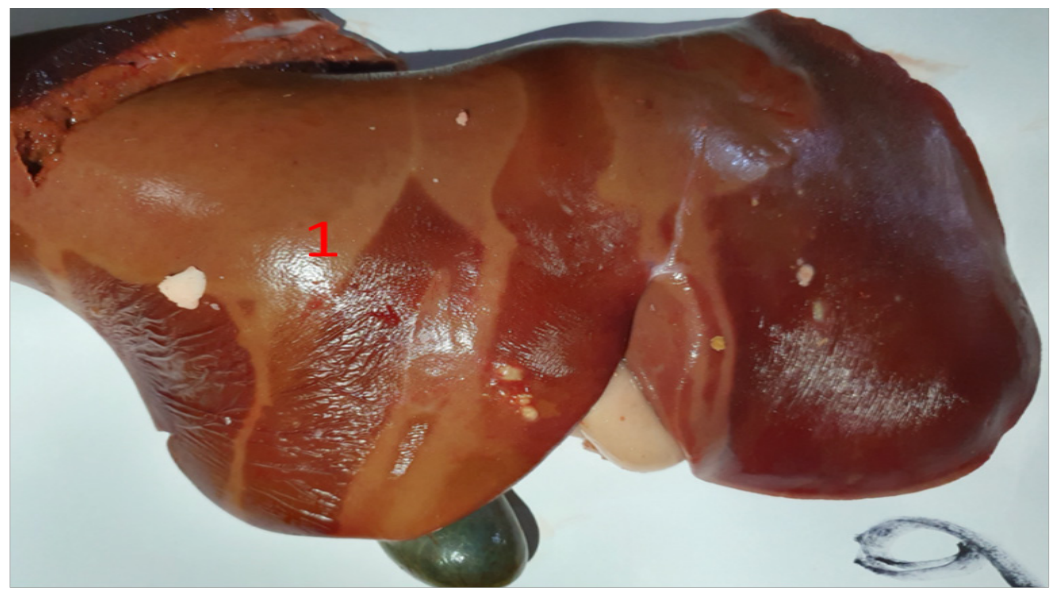

Fig. 9. Macroscopical observation of liver with fatty changes shows yellow discoloration (1), of part of liver compact to normal, soft and friable in texture. 


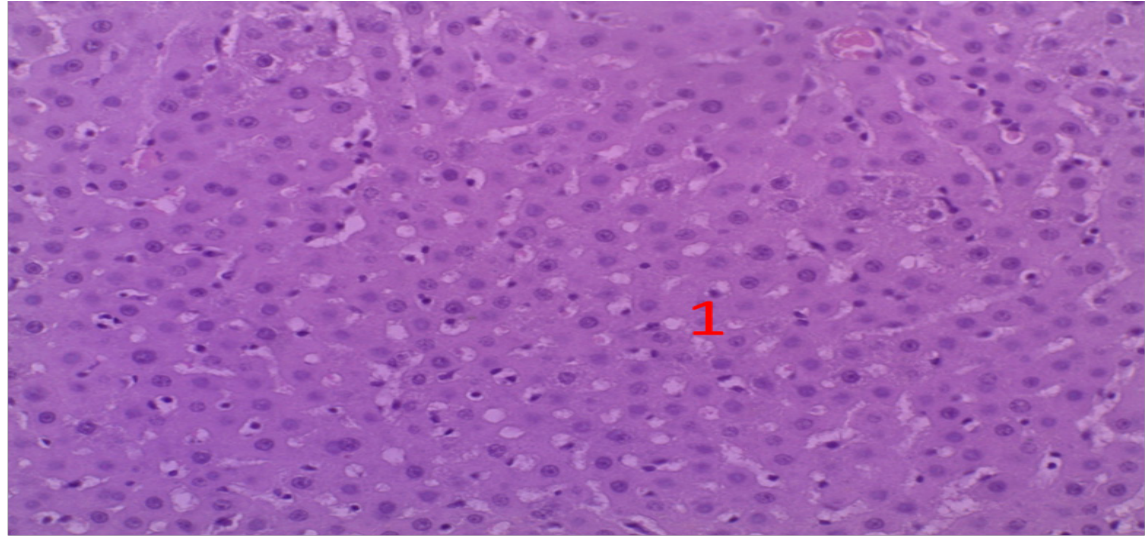

Fig. 10. Microscopical changes of liver with fatty changes shows variable empty spacers inside the hepatocytes as vacuolation (1), and pushing of the nuclei in the periphery of cells. [H\&E, 10X].

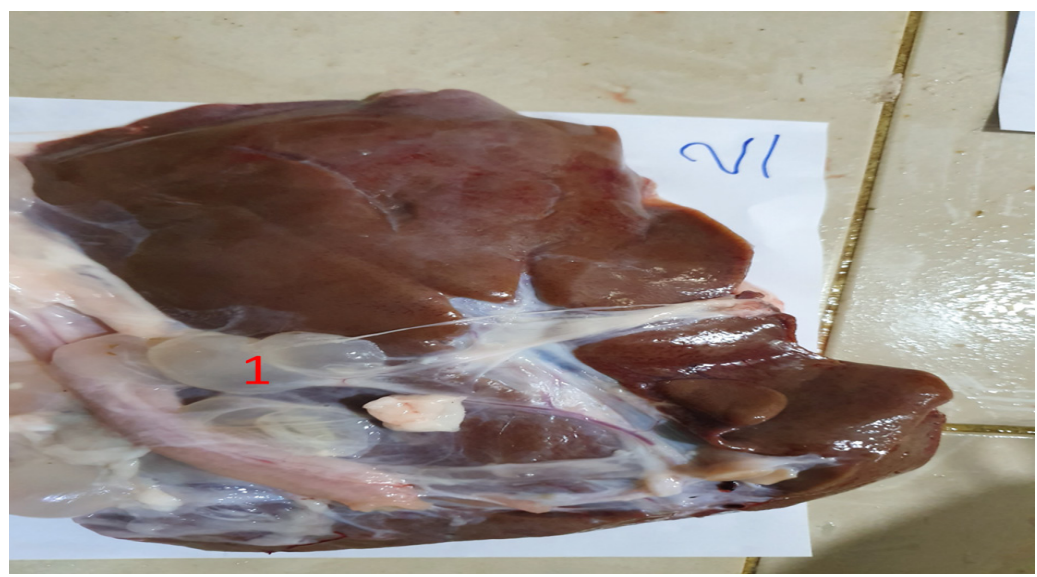

Fig. 11. Macroscopical picture of liver showing presence of different cysts of hepatitis cysticercosis (1), which is varies in size in the surface of liver and attached superficially with live parenchyma.

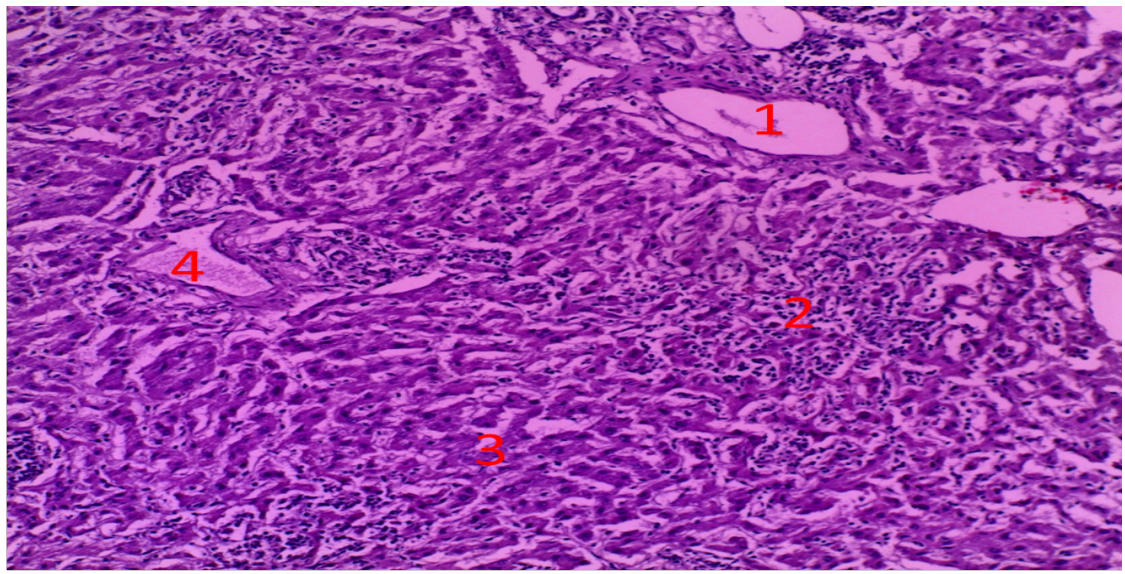

Fig. 12. Microscopical changes of liver with Cysticercus tenuicollis shows presence of cysts(1), associated with infiltration of mononuclear inflammatory cells (2), dilatation of sinusoids, and proliferation of bile duct (4).[H\&E].. 


\section{Discussion}

Liver diseases in ruminants causes significant economic losses in the most of countries, this study decided to investigate the lesions of liver in slaughtered sheep of Duhok abattoir and because studies are not available in this governorate and are almost non-existent, and due to the lack of available statistics, it was planned to carry out these field study, beside this study is the first of its kind in Duhok governorate, as it focused on macroscopic and microscopical liver lesions.

The results of this study show the overall incidence of these lesions was $99.8 \%$ and its distributed in the liver as hydatid cyst $62.8 \%$, necrosis $9.8 \%$, Liver abscess $8.9 \%$, Cysticecus tenuicollis cyst, with fatty changes was $15.6 \%$ respectively and Liver worms with inflammatory signs was $2.2 \%$. and our observed and variation through review of many of researches conducted in Iraq on the presence of liver lesions in sheep and most of these studies focus on only one type of lesions and one species of animals $[9,15]$.

In the current study show the liver affected with many of pathological lesions, especially as in cases of development of cysts and liver worms. Same observation was noted by other researcher dealing with hydatid cysts and Fascioliasis studies [16]. It postulated that the liver acts as the first barrier for the most of tape tapeworm oncospher which is penetrating from intestinal mucosa and reach to the portal circulation. Then, the embryos is carried out by circulation to the all parts of body, and depending to the large size of some lesions like oncospheres and metacercaria, most of them become arrested and settled in the liver. Beside the other research [17] which is mentioned that the possible variations in different species of animals and period of study which is play an important role for distribution of the oncosphere and other lesions to their final location in various organs.

The study show the highest lesions was recorded it was cyst which is closely resemble to the results of some authors[18, 19] because most fields of animal production are located on the banks of the River, and sometimes many animal breeders resort to grazing near the banks of the river, which allows chance of parasitic infestations as well as a lot of waste which are thrown into the river, as well as the carcasses of dead animals and capes bulk. Microscopically the result showed presence of cyst with thick membrane and infiltration of mononuclear inflammatory cells, the formation of these cyst occurs due ingestion of eggs of these parasite then hatching and reach to intestine by passing mucus membrane to circulation and finally localized in liver and forming hydatid cyst, and due to the proliferation and development of these cyst causing liver damage and as a result of reaction between these cyst and immune system [20,21], while in cases of liver worm histologically result found presence of liver damage due to migration of larvae of parasite to the bile duct forming inflammatory response either chronic or acute reaction which is manifested by infiltration of inflammatory cells, thinking of bile duct due to inflammatory reaction $[22-, 23]$

Beside the study showed that percentage rate of liver abscesses of the slaughtered sheep, and this result was close to what was stated by the researcher [24], as one of the most important three reasons which is leads to a high prevalence of liver abscesses in ruminants it is the concentrated ration that breeders resort to in certain periods in turn, the acidity of the rumen is reduced, which leads to irritation of the wall rumen, which gives the opportunity for bacteria to reach the liver through the portal causing the abscess, and this, was confirmed by [25]. Microscopically associated with infiltration of mononuclear inflammatory cells as focal necrotic foci due to inflammatory reaction between many of pathogenic agents which carried out either from circulation or from rumen resulting to forming abscesses [26].

As for what was noticed from the presence of congestion and hemorrhage visually, this necessarily leads to damaging the liver and this is consistent with what watched by some authors [27], but the results of the research differ in the percentage rate of these lesions it was recorded $2.2 \%$ and these are might be due to old lesion as chronic inflammation and fibrosis [28], also it was found to be occur frequently in sheep belonging to many of toxic agents through ingestion of environmental toxicants or plants during seasonal period of years. The chronic venous congestion of liver occurs commonly due to stagnation of blood within the central vein and adjacent sinusoids with subsequent necrosis of peripheral hepatocytes because of hypoxia. Furthermore, hepatic congestion is reported to occur due to either infectious causes [29] or noninfectious causes [30]. Macroscopically, the results obtained 
also indicated the presence of fatty change it's looked, enlarged and pale in colure and these degenerative and necrotic changes could be seen after exposure of liver to various toxin, hypoxia and anemia, which is in agreement with the reports of earlier workers [31]. Microscopically, the hepatocytes were enlarged with the presence of small multiple clear or pale vacuoles, within the cytoplasm, which is well in accordance with those described by Hassanein et al. [32].

\section{Conclusion}

It can be concluded that although the sheep slaughtered are apparently healthy, large percentages were found either to harbor certain pathological lesions or being infected with different diseases. Although the data obtained was for 5 months, it can be used as a preliminary baseline data in Duhok province for the future monitoring of these potentially important parasitic diseases and other causative agents for improving animal health, prevention of disease and reduction of economic losses by liver condemnations in sheep. A suggestive study should be undertaken to determine the etiology of those lesions and to investigate their possible role in zoonosis.

\section{Acknowledgement}

The author acknowledges the Duhok research center for preparation of tissue section; and Dr. Bassam Ali Asker for helping of collection of some of samples

\section{Funding statement}

This manuscript was funded by the college of veterinary medicine, University of Duhok, Iraq

\section{Conflict of Interest}

This article is no conflict of interest

\section{References}

1. Seal, C.J., and Reynolds, C.K. Nutritional Implication of Gastrointestinal and liver metabolism in ruminants. Nutrition Research Review., 6 ,185-208(1993).

2. Hussein, A.H. and Mohammed E. Evaluation of ultrasonography as a diagnostic tool for hepatic hydatid cysts in sheep. Turk. J. Vet. Anim. Sci ., 38, 409-441(2014).

3. Bacha, W.J. and Bacha, L.M. Color atlas of Veterinary Histology. $3^{\text {rd }}$ edition. John Wiley \& Sons, Ltd. USA. (2012).
4. Peter, F. N., Janine, A. G., Pierre, R. and Elyess, D. Border disease of sheep and goats. Vet. Rec., 29,327-340 (1998)

5. Tehrani, A., Javanbakht, J., Hassan, M.A.M., Zamani, M., Rajabian, M., Akbari, H. and Shafe, R. Histopathological and bacteriological study on hepatic abscesses of herrik sheep. J. Med. Microb. Diagn., 1(4), 32-41(2012)

6. Al-Mahmood, S.S., Farhan, S.S., Daoud, A.M., and Hamed, O.S. Pathological study of liver lesions in cattle slaughtered at Kirkuk province abattoir. Iraqi J. Vet. Sci., 31(1),7-16(2017).

7. Marif, H.F., Rashid, Z.M. and Muhamad, H.O. Liver fluke (fascioliasis). Int. J. Appl. Res., 2 (3),265-271(2016).

8. Wadood, E.A. Prevalence of hydatid cyst and hepatic fascioliasis in slaughtered animals at Basra abattoir. Basra. J. Vet. Res., 4(1),4-8(2005).

9. Khalil, K.Z. Prevalence of liver fluke and lungworm among slaughtered animals in Al-Najaf abattoir. AL-Qadisiya J. Vet. Med. Sci., 10,1117(2011)

10. Jarjees, M.T. and Al-Bakri, H.S. Incidence of hydatidosis in slaughtered livestock at Mosul. Iraq. J. Vet. Sci., 26(1), 21-25(2012)

11. Kadir, M.A., Ali, N.H. and Ridha, R.G.M. Prevalence of helminths, pneumonia and hepatitis in Kirkuk slaughter house, Kirkuk, Iraq. Iraq. J. Vet. Sci., 26(Suppl. III),83-88(2012)

12. Khaleel, Z.A., Abdulla, A. A. and Ali, H. A. Retrospective Survey of Liver flukes in Sheep and Cattle based on Abattoir Data in Al-Najaf Province, Iraq. Acta Scientific Veterinary Sciences, 1 (4),02-08 (2019).

13. Hadeel, T. Pulmonary and Hepatic lesions in slaughtered sheep in Mosul city. Tikrit Journal of Pure Science., 22 (6),25-33 (2017)

14. Luna, L.H. Manual of histologic staining methods of the armed forces institute of pathology. $3^{\text {rd }}$. Mc Graw-Hill Book Co. New York P. 3, 35, 236(1986).

15. Kasim, S.A., Nurdan, S. M., Mustafa, T. and Zainab, S. R. Study of bovine and ovine pulmonary and hepatic abscessation at Kirkuk abattoir. Plant Archives, 19(2), 1640-1644(2019)

Egypt. J. Vet. Sci. Vol. 53, No. 2 (2022) 
16. Fadhil, A.M. Comparative aspects on fertility and viability of hydatid cysts from goats, camels and buffaloes in Thiqar proveince southern Iraq. Basrah J. of Vet. Res., 5(2), 37-43(2006)

17. Al-Abbassy, S.N., Altaif, K.I., Jawad, A.K. and Al-Saqur, I. M. The prevalence of hydatid cysts in slaughtered animals in Iraq. Ann. Trop. Med. Parasitol., 74,185-187(1980).

18. Molan, A.L. Epidemiology of Hydatidosis and Echinococcosis in Theqar Province, Southern Iraq. Jap J. Med. Sci. Biol., 46,29-35(1993).

19. Saeed, I. Kapel, C., Saida, L.A., Wllingham, L. and Nansen, P. Epidemiology of Echinococcus granulosus in Arbil province Northern Iraq. 19901998. J. Heminthol., 74,83-88(2000).

20. Eckert, J. and Deplazes, P. Biological, epidemiological and clinical aspects of echinococcosis. Microbiol. Rev., 17,107-135 (2004).

21. Peña, C.C., Ramos-Solís, S., Barbosa-Cisneros, O., Rodríguez-Padilla, C., Tavizón-García, P. and Herrera-Esparza， R. Echinococcus granulosus Down Regulates the Hepatic Expression of Inflammatory Cytokines IL-6 and TNF $\alpha$ in Balb/C Mice. Parasite., 9(4), 351-356 (2002).

22. Cheng, H.C., Chang, W.L. and Chen, W.Y., Long-term outcome of pyogenic liver abscess: factors related with abscess recurrence. J. Clinic. Gastroenterol., 42(10):1110-1115(2008).

23. McGavin, M.D. and Zachary, J.F. Pathological Basis of Veterinary Disease, $4^{\text {th }}$ ed., Mosby, Elsevier, China., 70-92 (2007).

24. Khalid, A.Q. and Ahmed, A.M. Bacteriologic studies of liver abscesses of Awassi sheep in Jordan. Saunders Elsev. Sm Rumin Rese., 47,249253(2003).

25. Radostits, O.M., Gay, C.C., Hinchkliff, K.W. and Constable, P.D. Veterinary Medicine. $10^{\text {th }}$ ed. Sanders. Elsev., 383-384 (2010).

26. Alastair, B., Linda Stefan, and Mac Sween, H. Pathology of the liver, ed $7^{\text {th }}$ Churchill Livingstone. 313-362(2017)

27. Youkhana, S.O., Al- Sultan, I.I. and Ismail, H.K. Hepatic lesions in sheep and cattle in Mosul area. Iraqi J. of Vet. Sci., 13(1 ),21-25(2000)
28. Kumar, R., Patel, S.K., Rami Reddy, B.V., Sharma, R. and Singh, R. Pathomorphological alterations in liver of goats in Bareilly regions- A brief study. Ruminant Rcience, 4(1),181-184(2015).

29. Omotainse, S.O. and Anosa, V.O. Comparative histopathology of lymph nodes, spleen, kidney and liver in experimental trypanosomiasis. Onderstepoort J. Vet. Res., 76, 377-383 (2009).

30. Ozmaie, S., Akbari, G., Asghari, A., Sakha, M. and Mortazavi, P. Experimental oleander (Nerium oleander) poisoning in sheep: Serum biochemical changes a pathological study. Ann. Biol. Res., 4(1), 194-198 (2013).

31. Rasool, A.Y and Al- Dabhawi A.H. Pathological investigation of liver lesions in slaughtered cattle in Al-Najaf abattoir. Kufaa. J. for Vet. Med. Sci., 11(2), 12-22 (2020).

32. Hassanein, K. M., Sayed, M. M. and Hassan, A. M. Pathological and biochemical studies on enterotoxemia in sheep. Comp. Clin. Path., 26(3),513-518 (2017). 
دراسة مرضية لآفات الكبد في الأغنام في مسلخ دهوك

مهذى على عبدالله

قسم الامر اض و الاحياء المجهرية ـ كلية الطب البيطري - جامعة دهوك ـ العر اق.

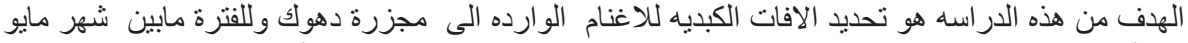

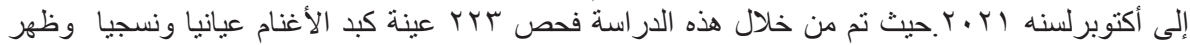

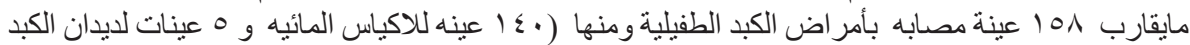

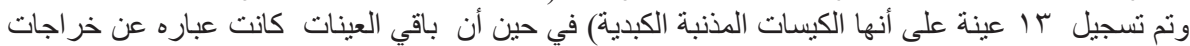

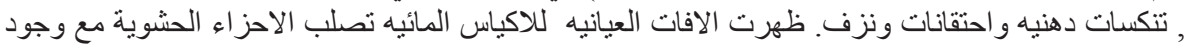

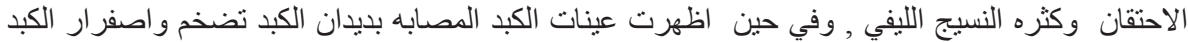

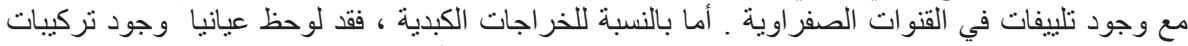

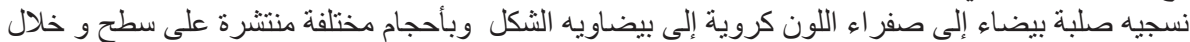

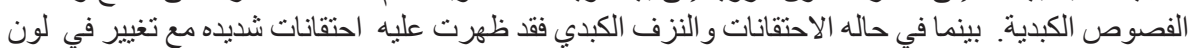

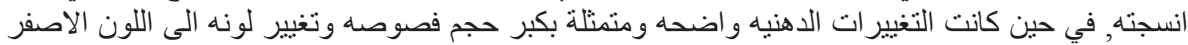

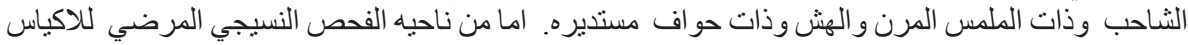

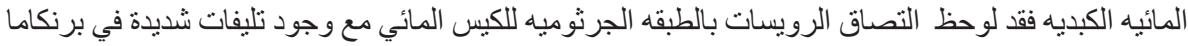

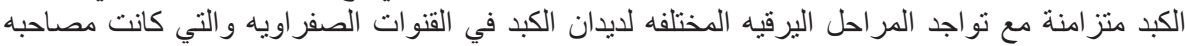

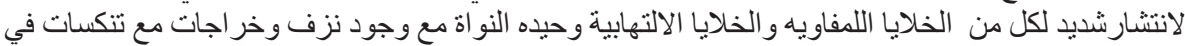

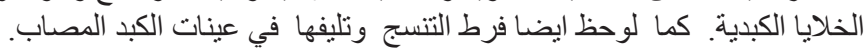

